\title{
The short-term tsunami forecast in the Pacific Ocean
}

\section{Yu. P. Korolev}

\author{
Institute of Marine Geology and Geophysics, FEB RAS, \\ Yuzhno-Sakhalinsk, Russia
}

\begin{abstract}
The problem of a short-term tsunami forecasting is actual at present. The proposed method of the short- term tsunami forecasting allows, based on information on tsunamis in the open ocean (for example, obtained by deep-sea bottom stations), with sufficient accuracy to give a detailed forecast of the expected tsunami at any point. The method works in a real time. To fulfill the forecast, the only a time of the start and the coordinates of the earthquake epicenter are required from the seismological service. The efficiency of the proposed method is tested on examples of local and remote tsunamis (for example, Tohoku 2011, Chile 2010, 2014). The method can be used not only by the centralized tsunami warning service, but also by any local service, if it is able to receive real-time tsunami information from remote sea-level stations in the open ocean.
\end{abstract}

\section{Keywords}

Tsunami, Short-term forecast, Tsunami alarm, False tsunami alarm

\section{References}

For citation: Korolev Yu.P. The short-term tsunami forecast in thePacific Ocean. Geosystems of Transition Zones, 2017, vol. 1, N 2, p. 3-17. doi:10.30730/2541-8912.2017.1.2.003-017 